\title{
SUGESTÕES DE LEITURA V.2, N.1 2016
}

Guia de Economia e Gestão em Saúde. Paola Zucchi, Marcos Bosi Ferraz. TamboréBarueri, SP: Editora Manole, 2010, 448 p. Livro que aborda a gestão da saúde por meio dos pontos importantes relativos ao funcionamento de hospitais e postos de atendimento. Os autores discutem aspectos relacionados às políticas públicas e o sistema privado de saúde no país, cobrindo tópicos como gerenciamento de doenças, regulamentação de serviços, gestão de medicamentos, sistemas de informação, telemedicina e ética.

\section{Gestão de Operações em Saúde para Hospitais, Clínicas, Consultorias e Serviços de} Diagnóstico. Libânia Rangel de Alvarenga Paes. Rio de Janeiro, RJ: Atheneu Editora, 2011, 192 p. Obra que apresenta a cadeia de valor em saúde e discute o papel dos prestadores de serviços, como consultórios, clínicas, hospitais e serviços de diagnósticos, nesta cadeia para melhor compreender suas características, sua realidade organizacional e aprimorar a gestão de suas operações. Explora a gestão de operações em diversos tipos de organizações, desde pequenos consultórios até hospitais de elevada complexidade e planos de saúde.

Promoção da Saúde no Contexto da Estratégia Saúde da Família. Ana Maria Fontenelle Catrib, Maria Socorro de Araújo Dias, Mirna Albuquerque Frota. Campinas, SP: Saberes Editora, 2012, 277 p. Livro que aborda a necessidade do poder público de assegurar aos cidadãos o direito de igualdade a oportunidades a partir da correlação da saúde com a qualidade de vida. Os textos destacam que o alcance da qualidade depende de abordagens intersetoriais da saúde e a promoção da saúde está relacionada aos valores da sociedade, com destaque para a saúde da família. 